\title{
Management of traumatic tympanic membrane perforation: a comparative study
}

This article was published in the following Dove Press journal:

Therapeutics and Clinical Risk Management

24 July 2017

Number of times this article has been viewed

\author{
Tianxi Gao' \\ Xiaoli $\mathrm{Li}^{2}$ \\ Juan $\mathrm{Hu}^{\prime}$ \\ Weijun $\mathrm{Ma}^{\prime}$ \\ Jingjing $\mathrm{Li}^{\prime}$ \\ Na Shao' \\ Zhenghui Wang' \\ 'Department of Otolaryngology- \\ Head and Neck Surgery, The \\ Second Affiliated Hospital of Xi'an \\ Jiaotong University, Xi'an, People's \\ Republic of China; ${ }^{2}$ Department of \\ Dermatology, The Second Affiliated \\ Hospital of Xi'an Jiaotong University, \\ Xi'an, People's Republic of China
}

Correspondence: Zhenghui Wang

Department of Otolaryngology-

Head and Neck Surgery, The Second

Affiliated Hospital of Xi'an Jiaotong

University, No 157 Xi Wu Road, Xi'an,

Shaanxi Province 710004, People's

Republic of China

Tel +862987679866

Fax +862987678421

Email ehui4298@163.com

\begin{abstract}
This prospective study was conducted to evaluate the efficacy of sea buckthorn oil patches in treating traumatic tympanic membrane (TM) perforations. We enrolled 370 patients with traumatic TM perforations of different sizes. These patients were randomly assigned to control group and treatment group. In the treatment group, a sterile cotton patch with sea buckthorn oil was used to cover the TM perforations. In the control group, patients were treated with a sterile cotton patch. The healing rate and time were compared between the two groups. We found that the overall healing rate was significantly higher in the treatment group than in the control group. For middle and large TM perforations, sea buckthorn oil treatment led to a significant increase in the healing rate. At 2 months after injury, the duration of healing was, generally, shorter in the treatment group than in the control group $(P<0.05)$. In conclusion, sea buckthorn oil patches are effective in treating middle and large TM perforations, which results in increased healing rates and decreased healing time.
\end{abstract}

Keywords: sea buckthorn oil, tympanic membrane, perforation, regeneration

\section{Introduction}

Traumatic tympanic membrane (TM) perforation is an injury of the eardrum, which is frequently faced by otolaryngologists. Common causes to traumatic TM perforation include rapid change in ear pressure (eg, occurring when flying and scuba diving), thermal or chemical burns, direct penetrating trauma, and barotrauma. ${ }^{1,2}$ The incidence of perforations of the TM due to trauma is on the increase consequent to trauma, and increased violence and accidents seen in present-day life. ${ }^{3}$ Ear buzzing, earache, and hearing loss are the major symptoms of TM perforation. In addition, TM perforation can increase the risk for middle ear infection or otitis media. ${ }^{4}$ Although most small perforations of the eardrum can be spontaneously healed, large TM perforations should be treated with myringoplasty. ${ }^{5}$

Sea buckthorn oil, which is extracted from the berries and seeds of the sea buckthorn plant, contains abundant vitamins, amino acids, and essential trace elements. ${ }^{6}$ A previous study has shown that sea buckthorn oil can be used to increase the healing rate of TM perforations. ${ }^{7}$ In the present study, we enrolled 370 patients with traumatic TM perforation and evaluated the therapeutic efficacy and safety of sea buckthorn oil in the treatment of different sizes of TM perforations.

\section{Materials and methods Patients}

This study was approved by the Ethics Review Board of the Second Affiliated Hospital of Xi'an Jiaotong University (2009-26). We enrolled 370 patients with traumatic 
TM perforation who were treated at our hospital between January 2010 and March 2015. There were 196 males and 174 females, with the mean age of $32.3 \pm 13.1$ years (range, 6-57 years). Overall, 226 cases presented a perforation in the left ear and 144 in the right ear. Triangle perforation was detected in 96 cases, spindle perforation in 83 cases, oval perforation in 62 cases, slit-shaped perforation in 78 cases, and irregular perforation in 51 cases. Inclusion criteria were history of traumatic injury, ear discomfort after injury, perforation of the eardrum, absence of infection, and no local treatment. Exclusion criteria were presence of otitis media, injury of auditory ossicles, allergic to sea buckthorn oil, and refusal to treatment and follow-up. Each patient signed the informed consent. Patients were prospectively and randomly assigned to control group $(n=183)$ and treatment group ( $\mathrm{n}=187)$. Treatment group was divided according to the size of perforation: small perforation, middle perforation, and large perforation.

\section{Classification criteria for perforation}

The classification was according to the size of perforation: small perforation, $<1$ quadrants or maximum diameter $<3 \mathrm{~mm}$; middle perforation, $>1$ quadrants and $<2$ quadrants or maximum diameter between 3 and $5 \mathrm{~mm}$; and large perforation, $>2$ quadrants or maximum diameter $>5 \mathrm{~mm}$.

\section{Treatment}

In the treatment group, a sterile cotton patch with sea buckthorn oil (Shannxi Aikang Shaji Company, Xi'an, People's Republic of China) was used to cover the TM perforation after iodophor disinfection of the outer ear canal. The patch was changed once every week. The control group was treated with routine observation without sea buckthorn oil. The external auditory canal of patients was disinfected with iodophor. The site of perforation was not treated and maintained dry ear, followed up once a week. Ear endoscope was used to observe the growth change of perforation between two groups. Meanwhile the two groups were to prevent infection, to maintain patency of the eustachian tube, to prevent a cold, and to prevent water. If there was a local infection, the treatment group was treated with oral antibiotics and without sea buckthorn oil for one time. The control group was given antiinfection treatment.

\section{Follow-up}

The healing of the TM perforation was monitored for 1 and 2 months. The healing rate was used as the evaluation index between the two groups. The average healing time and the healing area were observed and compared. Full healing was defined as complete closure of perforation, and partial healing as a reduction in perforation size. No change in perforation size was considered as treatment failure.

\section{Statistical analysis}

Statistical analysis was performed using SPSS 17.0 software (SPSS, Chicago, IL, USA). All data are presented as mean \pm SD. Differences in mean healing time (satisfied normality and homogeneity of variances) were analyzed using Student's $t$-test; the healing rate between two groups was using chi-square test (including the Pearson chi-square test and continuously corrected chi-square test). Subgroup data were analyzed by analysis of variance. A $P$-value of $<0.05$ was considered statistically significant.

\section{Results}

\section{Demographics of patients}

There was no significant difference about sex, age, cause of disease, and size of perforation between control group and treatment group (Table 1).

\section{Morphological features}

The newly formed TM had a smooth surface with similar thickness to normal counterparts. TM scarring was less frequently detected in the treat group than in the control group (Figure 1).

\section{Perforation healing rate}

At 1 month after perforation, the overall healing rates were $61.0 \%$ and $45.0 \%$ in the treatment group and control group, respectively $(P<0.01$; Table 2$)$. At 2 months after perforation, the overall healing rates of $71.6 \%$ and $54.1 \%$ were noted

Table I Demographics and clinical characteristics between two groups

\begin{tabular}{|c|c|c|c|c|c|c|c|c|c|}
\hline \multirow[t]{2}{*}{ Group } & \multirow[t]{2}{*}{ Case no } & \multicolumn{2}{|l|}{ Sex } & \multirow{2}{*}{$\begin{array}{l}\text { Age (years), } \\
\text { mean } \pm \text { SD }\end{array}$} & \multicolumn{2}{|c|}{ Causes of disease } & \multicolumn{3}{|c|}{ Size of perforation } \\
\hline & & Male & Female & & Direct damage & Indirect damage & Small & Middle & Large \\
\hline Treatment & 187 & I0I (54.0\%) & $86(46.0 \%)$ & $30.6 \pm 12.1$ & $153(81.8 \%)$ & 34 (I8.2\%) & 67 (35.8\%) & $62(33.2 \%)$ & $58(31 \%)$ \\
\hline Control & 183 & $95(51.9 \%)$ & $88(48.1 \%)$ & $33.4 \pm 13.7$ & 157 (85.8\%) & $26(14.2 \%)$ & 63 (34.4\%) & 59 (32.3\%) & 61 (33.3\%) \\
\hline
\end{tabular}



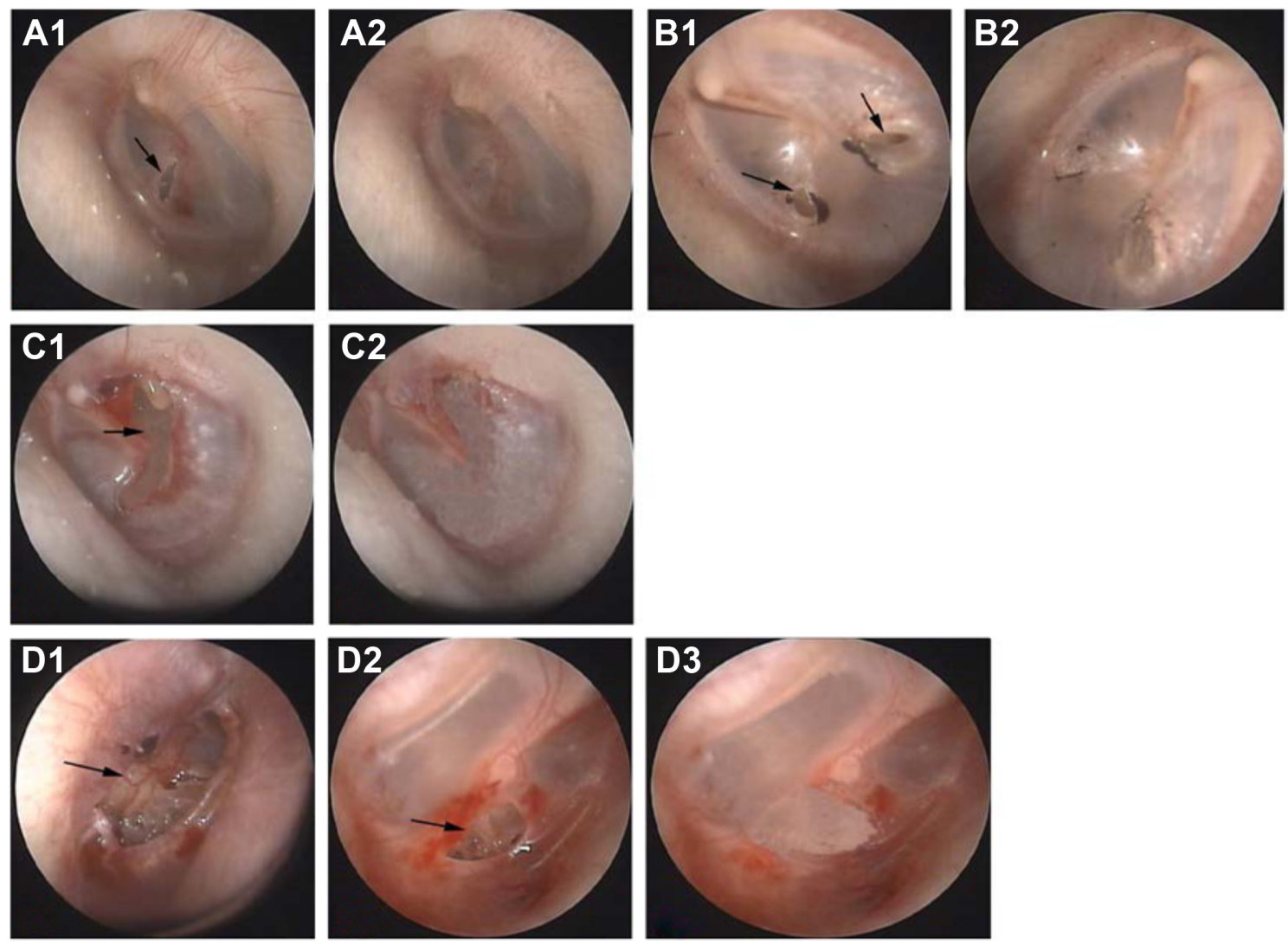

Figure I The typical cases of all kinds of membrane perforation.

Notes: A representative case of tympanic membrane perforation $(\mathbf{A} \mathbf{I})$ before treatment of small perforation; (A2) after treatment of small perforation; (BI) before treatment of small perforation in control group; (B2) self-healing of small perforation in control group; (CI) before treatment of middle perforation; (C2) full healing treatment for two times with sea buckthorn oil; (DI) before treatment of large perforation; (D2) after treatment for three times with sea buckthorn oil; and (D3) full healing after treatment for five times with sea buckthorn oil.

in the treatment group and the control group, respectively $(P<0.01$; Table 3$)$. For middle and large TM perforations, the healing rates were $59.7 \%$ and $39.6 \%$ in the treatment group and $13.6 \%$ and 0 in the control group, respectively, at 1 month after perforation ( $P<0.05$ for both comparisons). The differences in the healing rates for middle and large TM perforations remained significant between the two groups at 2 months after perforation $(P<0.05)$. In contrast, the two groups did not differ significantly in the healing rates for small TM perforations $(P>0.05)$.

Table 2 Comparison of healing rate between two groups for I month

\begin{tabular}{lllll}
\hline Group & Cases no & Full healing & Partial healing & Failure \\
\hline \multicolumn{2}{l}{$\begin{array}{l}\text { Treatment } \\
\text { Small }\end{array} 67$} & $54(80.6 \%)$ & $10(15 \%)$ & $3(4.4 \%)$ \\
Middle & 62 & $37(59.7 \%)$ & $21(33.9 \%)$ & $4(6.4 \%)$ \\
Large & 58 & $23(39.6 \%)$ & $32(55.2 \%)$ & $3(5.2 \%)$ \\
Control & & & & \\
Small & 63 & $45(71.4 \%)$ & $14(22.2 \%)$ & $4(6.4 \%)$ \\
Middle & 59 & $8(13.6 \%)$ & $27(45.8 \%)$ & $34(57.6 \%)$ \\
Large & 61 & 0 & $16(26.2 \%)$ & $45(73.8 \%)$ \\
\hline
\end{tabular}

\section{Duration of perforation full healing}

At 1 month after injury, treatment with sea buckthorn oil significantly reduced the time to full healing for small TM perforations, compared to the control group $(P<0.05$; Table 4). However, with regard to middle and large TM perforations, the duration of healing did not differ significantly between the treatment and control groups $(P>0.05)$. At 2 months after injury, the duration of healing was generally shorter in the treatment group than in the control group, irrespective of the size of TM perforations $(P<0.05)$.

Table 3 Comparison of healing rate between two groups for 2 months

\begin{tabular}{|c|c|c|c|c|}
\hline Group & Cases number & Full healing & Partial healing & Failure \\
\hline \multicolumn{5}{|c|}{ Treatment } \\
\hline Small & 67 & $62(92.5 \%)$ & $2(3 \%)$ & $3(4.5 \%)$ \\
\hline Middle & 62 & $50(80.6 \%)$ & $8(12.9 \%)$ & $4(6.5 \%)$ \\
\hline Large & 58 & 38 (65.5\%) & $12(20.7 \%)$ & $8(13.8 \%)$ \\
\hline \multicolumn{5}{|c|}{ Control } \\
\hline Small & 63 & $59(93.7 \%)$ & 0 & $4(6.3 \%)$ \\
\hline Middle & 59 & $32(54.2 \%)$ & $3(5.1 \%)$ & $24(40.7 \%)$ \\
\hline Large & 61 & $8(13.1 \%)$ & $11(18 \%)$ & 42 (68.9\%) \\
\hline
\end{tabular}


Table 4 Comparison of duration of perforation healing between two groups (days)

\begin{tabular}{lllll}
\hline $\begin{array}{l}\text { Observation } \\
\text { time }\end{array}$ & $\begin{array}{l}\text { Number } \\
\text { of healing }\end{array}$ & Small & Middle & Large \\
\hline $\begin{array}{l}\text { Treatment } \\
\text { I month }\end{array}$ & 114 & $13.24 \pm 7.12$ & $19.63 \pm 8.12$ & $29.38 \pm 11.22$ \\
2 months & 150 & $16.45 \pm 9.67$ & $26.79 \pm 10.36$ & $29.97 \pm 10.89$ \\
Control & & & & \\
I month & 53 & $19.91 \pm 6.54$ & $24.39 \pm 9.51$ & - \\
2 months & 99 & $26.17 \pm 13.31$ & $38.76 \pm 13.52$ & $47.97 \pm 9.85$ \\
\hline
\end{tabular}

Note: Data presented as mean \pm standard deviation.

\section{Discussion}

Traumatic TM perforation is a common clinical condition and most of them heal spontaneously within 4 weeks. ${ }^{8}$ Surgical treatment is indicated if TM perforations are symptomatic and large. A prospective, nonrandom study by Sayin et al demonstrated that there was a spontaneous healing rate of $85.6 \%$ among 97 patients with TM perforations (59.8\% small, $36.1 \%$ middle, and $4.1 \%$ large perforations). ${ }^{9}$ In this study, we showed that the differences between the overall healing and spontaneous healing rates were statistically significant in the control group. The spontaneous healing rate rises with time, but decreases with the increase in the perforation size. The higher spontaneous healing rate observed in previous studies may be due to a smaller percentage of large perforations and prolonged duration. When the waiting time for spontaneous perforation healing is long, the risk for otitis media was increased. ${ }^{10}$ In addition, there is an evidence that the site of perforation and blood supply also affect the spontaneous healing of TM perforations. ${ }^{11}$ Therefore, it is recommended that large TM perforations need active therapy.

Many efforts have been made to develop drug-loaded patches for repairing TM perforations. For instance, gelatin sponge, basic fibroblast growth factor, and sea buckthorn oil have shown the ability to facilitate the healing of TM perforations. ${ }^{12-14}$ These agents can promote epithelial cell proliferation and cell-cell connection, consequently accelerating the repair of perforations and improving hearing. It is known that sea buckthorn oil is rich in vitamins, amino acids, and essential trace elements. The content of vitamin $\mathrm{C}$ is 35 -fold greater in sea buckthorn oil than in oranges. ${ }^{15}$ Sea buckthorn oil has a high level of zinc (2.11 pm relative to the serum level of $0.8-1.2 \mathrm{ppm}$ in humans). It has been reported that zinc can enhance the healing of traumatic injury. ${ }^{16}$ Compelling evidence indicates that sea buckthorn oil has the ability to promote tissue regeneration and no toxicity to the ear. ${ }^{17,18}$ Zhang and Fan reported that treatment with sea buckthorn oil remarkably enhances the proliferation of TM epithelial stem cells and their migration to lesions, which are coupled with increased amounts of mitochondria and thickening of the rough endoplasmic reticulum. ${ }^{19}$ Other researchers found that flavonoids of sea buckthorn oil can induce blood vessel dilatation and aid in the recovery of middle ear function. ${ }^{20}$

In this prospective study, we compared the healing of TM perforations in the sea buckthorn oil and control groups. We found that the overall healing rate differed significantly between the two groups at different time points. The application of sea buckthorn oil patches promoted the healing of TM perforations. Compared to the control group, the duration of healing was significantly shorter in sea buckthorn oil group. Therefore, our data indicate that sea buckthorn oil patches are beneficial in the repair of TM perforations, especially middle and large perforations, which can increase healing incidences and reduce healing duration.

It is estimated that repair of TM perforations using patches can lead to a healing rate of $80 \%-95 \%$, which is comparable to that achieved by myringoplasty. ${ }^{21}$ The patchbased treatment strategy has a cost-effective advantage and does not need autologous tissues. ${ }^{22}$ The regenerated TM by myringoplasty has a different structure than that of normal TM, which hampers the improvement of patient hearing. ${ }^{23}$

\section{Conclusion}

Sea buckthorn oil patches are beneficial in repairing middle and large TM perforations, increasing healing rates and shortening the healing time. This treatment strategy has a cost-effective and low-risk advantage over surgical approaches. Meanwhile, it can save the medical expenses and is worthy of clinical use.

\section{Disclosure}

The authors report no conflicts of interest in this work.

\section{References}

1. Lou ZC, Lou ZH, Zhang QP. Traumatic tympanic membrane perforations: a study of etiology and factors affecting outcome. Am J Otolaryngol. 2012;33(5):549-555.

2. Van Rijswijk JB, Dubach P. Binaural tympanic-membrane perforations after blast injury. $N$ Engl J Med. 2017;376(19):e41.

3. Sarojamma, Saurabh R, Satish HS. A clinical study of traumatic perforation of tympanic membrane. IOSR J Dental Med Sci. 2014;13(4): 24-28.

4. Orji FT. Non-explosive blast injury of the tympanic membrane in Umuahia, Nigeria. Niger J Med. 2009;18(4):365-369.

5. Orji FT, Agu CC. Patterns of hearing loss in tympanic membrane perforation resulting from physical blow to the ear: a prospective controlled cohort study. Clin Otolaryngol. 2009;34(6):526-532.

6. Gao S, Guo Q, Qin C, Shang R, Zhang Z. Sea buckthorn fruit oil extract alleviates insulin resistance through the PI3K/Akt signaling pathway in type 2 diabetes mellitus cells and rats. J Agric Food Chem. 2017;65(7): $1328-1336$. 
7. Jiang Y, Hei Y, Wang W. Clinical analysis of tympanic membrane perforation with sea buckthorn oil (45 cases). J Clin Otorhinolarynol. 1999;7(1):41.

8. Pusz MD, Robitschek J. Traumatic hearing loss in the context of blast-related tympanic membrane perforation. Mil Med. 2017;182(1): e1645-e1648.

9. Sayin I, Kaya KH, Ekizoğlu O, Erdim I, Kayhan FT. A prospective controlled trial comparing spontaneous closure and Epifilm ${ }^{\circledR}$ patching in traumatic tympanic membrane perforations. Eur Arch Otorhinolaryngol. 2013;270(11):2857-2863.

10. Lou ZC. The eardrum bridge of traumatic tympanic membrane perforation. Eur Arch Otorhinolaryngol. 2016;273(12):4653-4654.

11. Lou ZC, Lou ZH, Tang YM. Comparative study on the effects of EGF and $\mathrm{bFGF}$ on the healing of human large traumatic perforations of the tympanic membrane. Laryngoscope. 2016;126(1):E23-E28.

12. Chen JH. Comparison of FGF-2, FLOX, and gelfoam patching for traumatic tympanic membrane perforation. Otol Neurotol. 2016;37(10): 1679-1680.

13. Zhang D, Huang Z, Sun P, et al. Acceleration of healing of traumatic tympanic membrane perforation in rats by implanted collagen membrane integrated with collagen-binding basic fibroblast growth factor. Tissue Eng Part A. 2017;23(1-2):20-29.

14. Gür ÖE, Ensari N, Öztürk MT, et al. Use of a platelet-rich fibrin membrane to repair traumatic tympanic membrane perforations: a comparative study. Acta Otolaryngol. 2016;136(10):1017-1023.

15. Diandong H, Feng G, Zaifu L, Helland T, Weixin F, Liping C. Sea buckthorn (Hippophae rhamnoides L.) oil protects against chronic stress-induced inhibitory function of natural killer cells in rats. Int $J$ Immunopathol Pharmacol. 2016;29(1):76-83.
16. Zeb A, Ullah S. Sea buckthorn seed oil protects against the oxidative stress produced by thermally oxidized lipids. Food Chem. 2015; 186:6-12.

17. Zhang XT, Fan YL, Cheng YX. The effect on cochlear function with sea buckthorn oil in guinea pigs. Chin J Integr Med. 1997;(Suppl 1):180.

18. Zhang XT, Fan YL. The effect of seabuckthorn oil on traumatic tympanic membrane perforation with transmission electron microscopy. J Clin Otorhinolaryngol. 1997;11:518-520.

19. Zhang XT, Fan YL. The effect of seabuckthorn oil on traumatic tympanic membrane perforation in guinea pigs. Chin Clin Otorhinolaryngol. 2011;15(7):35-39.

20. Wu Y, Wang BW. Effects of seabuckthorn oil on microcirculation. Pharmacol Clin Chin Materia Medica. 2000;6:18-19.

21. Altuntaş EE, Sümer Z. Biocompatibility evaluation of cigarette and carbon papers used in repair of traumatic tympanic membrane perforations: experimental study. Eur Arch Otorhinolaryngol. 2013;270(1): 81-86.

22. Park MK, Kim KH, Lee JD, Lee BD. Repair of large traumatic tympanic membrane perforation with a Steri-Strips patch. Otolaryngol Head Neck Surg. 2011;145(4):581-585.

23. Eliades SJ, Limb CJ. The role of mastoidectomy in outcomes following tympanic membrane repair: a review. Laryngoscope. 2013;123(7) 1787-1802.
Therapeutics and Clinical Risk Management

\section{Publish your work in this journal}

Therapeutics and Clinical Risk Management is an international, peerreviewed journal of clinical therapeutics and risk management, focusing on concise rapid reporting of clinical studies in all therapeutic areas, outcomes, safety, and programs for the effective, safe, and sustained use of medicines. This journal is indexed on PubMed Central, CAS,

\section{Dovepress}

EMBase, Scopus and the Elsevier Bibliographic databases. The manuscript management system is completely online and includes a very quick and fair peer-review system, which is all easy to use. Visit http://www.dovepress.com/testimonials.php to read real quotes from published authors.

Submit your manuscript here: http://www.dovepress.com/therapeutics-and-clinical-risk-management-journal 